\title{
Kurumsal Bakım Sektöründe Ageism: Yaşlı Bakım Personelinin Yaşlanma ve Yaşlılığa İlişkin Ayrımcı Tutumlarının Nedenleri ve Müdahale Önerileri
}

\author{
Ageism in Institutional Care: Causes of the Discriminatory Attitudes of Older \\ Care Staffs towards Ageing and Old Age and Intervention Strategies
}

\begin{abstract}
Özgür ARUN*
Deniz PAMUK ${ }^{* *}$

Öz: Yaşam süresinin uzamasıyla beraber yaşlılara hizmet veren bakım kurumlarına ihtiyaç artmaktadır. Bu kurumlarda yaşlılarla yüzyüze iletişim halinde olan bakım personelinin ageism düzeylerinin belirlenmesi bakımın kalitesi açısından önemlidir. Bu nedenle, yaşlanma ve yaşlılığa ilişkin tutumlarını analiz etmek üzere, Antalya'da bakım kurumlarında çalışan 102 bakım personeline sosyodemografik bilgi formu ve Fraboni Ageism Ölçeği uygulanmıştır. Analizler sonucunda, bakım sektöründeki deneyim, son işyerindeki çalışma süresi ve toplumsal cinsiyetin, bakım personelinin ageism düzeyini etkileyen faktörler olduğu anlaşılmaktadır. Ageismin alt boyutları olan ayrımcılık, önyargı ve kaçınma boyutları değerlendirildiğinde, haftalık yasal çalışma süresinin üzerinde çalışan bakım personelinin, 3 kat daha fazla ayrımcı tutuma sahip olduğu görülmektedir. Ayrıca bakım personelinin kaçınma düzeyi, bakım sektöründeki deneyimle doğru orantılı olarak artmaktadır.
\end{abstract}

Anahtar sözcükler: Ageism, yaşlı bakımı, kurumsal bakım, bakım personeli, yaş ayrımcılı̆̆ı, lojistik regresyon

Abstract: With increasing life expectancy, the need for care institutions for the elderly is also increasing. In terms of the quality of care for older people, the evaluation of the levels of ageism amongst the staff who work with the elderly housed in these institutions is important. In consequence, the standard questionnaire, which is composed of socio-demographic variables and the Fraboni Scale of Ageism, was given to 102 care staff workers in the city of Antalya. The analysis of these results indicates that the length of time working in the older adult care sector, the length of time working within an institutional setting, and gender do have effects upon the levels of ageism amongst care staff. In addition, the levels of sub-scales of ageism (discrimination, prejudice and avoidance) were also analysed. The results show the number of hours worked affected the degree/level of both discrimination and prejudice. It is evident from the results obtained that those care staff who work for longer than the legal number of working hours were three times more likely to exhibit discriminatory attitudes. Further, the avoidance levels exhibited by the care staff increased linearly with the length of experience in working within the elderly adult care sector that a member of the care staff had.

Keywords: Ageism, older adult care, institutional care, care staff, age discrimination, logistic regression

\footnotetext{
* Doç. Dr., Akdeniz Üniversitesi, Edebiyat Fakültesi, Gerontoloji Bölümü, Antalya, arun@akdeniz.edu.tr

** M.A., Akdeniz Üniversitesi, Edebiyat Fakültesi, Gerontoloji Bölümü, Antalya, dnzpmk@gmail.com Bu çalışma, Gerontoloji Bölümü bünyesinde faaliyet gösteren Sosyal ve Ekonomik Araştırmalar Merkezi (SERES) tarafından desteklenmiştir.
} 


\section{Giriş}

Türkiye'de 1960'da kadınlar için 54, erkekler için 51 yıl olan doğumda beklenen yaşam süresi, 2013 yılı için kadınlarda 79.2, erkeklerde 74.7 yıla ulaşmıştır (TUİK, 2013). Yaşam süresinin uzaması ile birlikte, yaşlı nüfusta da önemli bir artış görülmektedir. 1960 yılından 2013 yılına kadar geçen sürede Türkiye nüfusu 3 kat artarken, 60 yaş üstündeki nüfus 7 kat artış göstermiştir (Arun, 2013). Yaşlı nüfus içinde bilhassa 80 yaş ve üzeri nüfusun artış hızı oldukça dikkat çekicidir (Arun, 2014). 2050 y1lına gelindiğinde ise Türkiye'deki ortalama yaşam süresinin 80 yılı aşacağı ve Avrupa'daki yaşam süresiyle eşitleneceği tahmin edilmektedir (Behar, 2006; akt. Arun, 2014). Ancak uzun yaşam, kapsayıcı sağlık ve bakım hizmetleri olmadığında bir dezavantaja dönüşmekte, hastalıkla birlikte geçirilen yılların da uzaması anlamına gelmektedir. Arun ve Çakıroğlu'nun (2013) güncel çalışması, Türkiye'de 65 yaş üzerindeki bireylerin \%56'sının kronik sağlık sorunları yaşadığını göstermektedir. Birden fazla hastalıkla geçirilen yılların uzaması, bakım kurumlarına duyulan ihtiyacı da artırmaktadır (Lovell, 2006, 22).

Günümüzde Türkiye'de kurumsal bakım uygulamaları, kamuya ait ya da özel kuruluşlar aracılığıyla yapılmaktadır (Giray et alii, 2008; Ünalan, Soyuer, \& Elmalı, 2012). Kamuya ait rehabilitasyon merkezlerinin ve özel kuruluşlara ait bakım ve rehabilitasyon merkezlerinin sayıs1 2012 yılı itibariyle 250 merkezden oluşmaktadır (Engelli ve Yaşlı Hizmetleri Genel Müdürlügüu, 2013). Bakım kurumları ve rehabilitasyon merkezlerinde çalışan bakım personeline ilişkin Türkiye'de çok sayıda çalışma bulunmaktadır. Son 10 yılda gerçekleştirilen bu çalışmalara bakıldığında 5 başlıkta toplamak mümkündür:

a) Bakım personelinin tükenmişlik düzeyleri (Mandıracıoğlu, \& Çam, 2004; Bektaş, \& İlhan, 2008; Çimen et alii, 2012; Özçakar et alii, 2012).

b) Bakım personelinin iş memnuniyeti (Şimşek, 1995, Çimen et alii, 2012).

c) Bakım personelinin yaşıı mahremiyetine ilişkin tutumları (İzgi et alii, 2013).

d) Düşme riskine ilişkin görüşleri (Emiroğlu, \& Yıldırım, 2007).

e) Sorunları ve yaşlılar ile ilgili görüşleri (Mandıracıŏglu, \& Çam, 2004) ve bakıcılık hakkında görüşleri (Ünalan, Soyuer, \& Elmalı, 2012).

Bakım personeline yönelik çalışmalar, bakım kalitesinin artırılmasının temelde personelin sosyo-ekonomik ve psikolojik durumunun iyileştirilmesiyle sağlanabileceğine vurgu yapmaktadır. Ancak Türkiye'de bakım personelinin hizmet verdiği kesime karşı sergilediği tutum, ageism perspektifinden Türkiye literatüründe dikkat çekici düzeyde araştırmaların konusu olmamıştır. Oysa, yaşlanma ve yaşlılığa ilişkin olumlu ya da olumsuz tutumlar, bakımın kalitesiyle doğrudan ilişkilidir (Wade, 1999). Negatif tutumlar, ageist davranışlara yol açtığı gibi, genç yetişkinler arasında yaşlıların refahlarının da daha az önemli olduğu şeklinde algılanmasını da kolaylaştırmaktadır. Böylece, ageism bazı genç yetişkinlerin yaşlıları ihmali, suistimali ve diğer istismar türlerinin ortaya çıkmasına yol açmaktadır (Quinn, \& Tomita, 1986). Bilgi eksikliği, toplumsal mitler ve önyargılar, bakım sağlayıcılarının kaliteli bir bakım sunmasına engel teşkil eden faktörler arasında sayılmaktadır (Lantis, Green, \& Joyce, 2002). Bu bakımdan, kurumsal düzeyde bakım veren personelin yaşlılık ve yaşlanmaya ilişkin tutumları, bakımın kalitesini de belirleyen önemli faktörlerden birisidir. Bu çalışma, yukarıdaki arka plandan hareketle, Türkiye'de bakım verenlerin yaşlanma ve yaşlılığa ilişkin tutumları nedir? sorusuna yanıt arayacaktır.

\section{Teorik Arkaplan: Ageism}

Butler (1989), yaşlı bireylere karşı sistematik önyargıları ve ayrımcılığı "ageism" kavramıyla tanımlamaktadır. Ona göre ageism, ırkçılık ve cinsiyet ayrımcılığından sonraki en son önyargı, en son ayrımcılık ve en zalim reddetme biçimidir (Butler, 1989, 139). Literatürde, önyarg1 
kavramı çerçevesinde yapılan çalışmalar stereotipleme, önyargı ve ayrımcılık olarak üç başlıkta tartışılmaktadır (Dozois, 2006):

1. Stereotipleme: Bireyin uzun süreli hafizasında belirli bir sosyal grup hakkında bilgi yapıları ve şemalar oluşturma, tasarlama süreçlerini tanımlar.

2. Önyarg1: Günlük kullanımda stereotipleme ile karşılaştırılabilir. Ancak literatürde bu terim özellikle bir sosyal gruba karşı duygusal ya da tutumsal yanıtları tanımlamak için kullanılır. Bu yüzden önyargı, duygusal süreçleri tanımlar.

3. Ayrımcılık: Bu terim stereotiplemenin davranışsal sonuçlarını açıklar (s. 2).

Ageism ise yukarıda sayılan bu üç mekanizmayı da içeren (Breckler, 1984; Eagly, \& Chaiken, 1998; akt. Cuddy, \& Fiske, 2002, 3), yaşlı bireylere ve yaşlanma sürecine dair kökleri daha derinde olan; sosyal olarak inşa edilmiş olumsuz inançlardır. Bunlar, kurumlar, kurallar ve gündelik yaşam yolu ile içselleştirilmekte, ayrıca yaş ayrımcılığını da beslemektedir (Hewstone, 1989, McGlane, \& Fitzgerald, 2005; Clark, 2009).

Butler ve Lewis'e (1973) göre, ageism, genç bireylerin yaşlıları kendilerinden farklı olarak görmelerine yol açmakta, bu durum, yaşlıların insan oldukları gerçeğini ortadan kaldırarak, yaşlanmaya karşı korku ve dehşeti artırmaktadır (McGlane, \& Fitzgerald, 2005).

Butler (1969) bu konuda şunu söylemektedir:

Ageism, gençlik ve orta yaşta, derinlere işlemişs tedirginlik, yaşlılık, hastalık, engellik ve güçsüzlük korkusu, faydasızlık ve ölüme karşı kişisel bir tiksinti ve kaçınma hali ortaya çıkarır (McGlane, \& Fitzgerald, 2005).

Butler’a göre, (1969) ageism birbiri ile ilişkili ancak birbirinden bağımsız üç boyuta sahiptir.

1. Yaşlı bireye, yaşl1lığa, yaşlanma sürecine ve bireyin kendi yaşlılığına karşı önyargılı tutumlar

2. Yaşlı bireylere karşı ayrımcı uygulamalar,

3. Kalıplaşmış inançları (stereotipler) sürdürecek şekilde, yaşlıların yaşam memnuniyetini azaltıcı ve kişisel itibarına zarar verici kurumsal uygulamalar ve politikalar (Nelson, 2002; Clark, 2009).

Ageism, gündelik yaşamda bireyler arasında iletişime de olumsuz yansımaktadır. Araştırmacılar tarafından, iki önemli olumsuz iletişim tarzı tanımlanmıştır: Overaccomandation (yaşlının işi yapamayacağı önyargısıyla işlerini onun yerine yapma) ve bebek konuşması (Nelson, 2005) yaşlı bireylerin maruz kaldığı ageismin en önemli göstergesidir.

Ayrıca ageism, yaşı bireylerin bir yük olarak algılanmasına neden olmaktadır. Bu da bilhassa sosyal dışlanmaya neden olmaktadır. Yaşıı bireyde özgüven eksikliğine, ulaşabileceği hizmetlerin sayısında ve kalitesinde azalmaya neden olmaktadır (Nelson, 2005). Bu nedenle ageism toplumsal katılımın önündeki engellerden birisidir.

Sağlık ve sosyal bakım hizmetlerinde yaş önyargılı tutumlar;

I. kaçınma (örn. yaşlı yerine aile bireyi ile konuşma), katlanamama,

II. tartışmayı kontrol etme,

III. yüksek sesli ve abartılı tonlama,

IV. bebeksi konuşma, basitleştirilmiş konuşma ya da aşırı samimi konuşma,

V. bağırma,

VI. yaşlı bireyin konuşmasını dinlememe, 
VII. yaşlının konuşmasına karşı dışlayıcı yorumlar,

VIII. aşırı anaç tavırlar (ya da aşırı şefkat),

IX. bağımlı davranışa karşı seçici takviye (selective reinforcement) ve kınama gibi boyutları içermektedir (Caporael, 1981; Kemper, 1994; Ryan, Hummert, \& Boich, 1995).

Ageist tutumlar ve buna bağlı profesyonel bakış açısının baskınlığı, yaşlıların bakım evinde nasıl yaşaması gerektiği, bağımlılık ile kayıpların yönetimi ile ilgili konulardaki yanlış varsayımlara ve hatalı planlamalara da yol açmaktadır (Clark, 2009). Böylece, "sağlık personelinin yaşlı bireylere yönelik olumsuz önyargı, değer, inanç ve tutumlarl, yaşlı bireylere verilen baklmin kalitesine de yansimaktadır" (Ünalan, Soyuer, \& Elmal1, 2012). Bunun sonucunda, yaşlı bireyler gençlere göre daha düşük kalitede kurumsal bakım alabilmektedir (Clark, 2009). Chandhury'nin (2008) belirttiği üzere, bakım kurumlarında demanslı bireylere sunulan hizmetin kalitesi, bakım personeliyle bakım alan arasındaki iletişim tarafından da şekillendirilmektedir. Dolayısıyla ageism, bakım sürecinde, bakım alan ve veren arasındaki iletişimi de zedeleyecek şekilde açığa çıkmaktadır (Weirds, 2004).

Yaşlı bireylerce algılanan ayrımcılık, çeşitli sağlık problemlerine de yol açmaktadır. Ageisme maruz kalan yaşlıların, yüksek kan basıncı problemi yaşadığı (Lewis et alii, 2009) ve yaşlanma ile ilgili negatif stereotiplere maruz kalan yaşlıların daha fazla kardiyovasküler stres yaşadıkları belirtilmektedir (Westerhof, \& Barret, 2005, 129).

Tüm bu çalışmaların ışığında, yaşlanan Türkiye'de gittikçe artan bakım ihtiyacının karşılanması ve bakım kalitesinin yükseltilmesi için, kurumsal bakım personelinin ageism düzeyi, ileri dönemlerde alınacak önlemler ve uygulamaların belirlenmesi açısından incelenmesi gereken bir konudur. Dolayısıyla, bu çalışmada "Türkiye'de yaşlı bakım personeli yaşlılara karşı nasıl bir tutum sergilemektedir?"; "Yaş̧l bakım personelinin, yaşlanma ve yaşllliğa ilişkin sergilediği olumlu ya da olumsuz tutumlar, hangi bağlamda değerlendirilmelidir?" ve "Olumlu ya da olumsuz tutumları etkileyen faktörler nelerdir?" sorularına yanıt aranacaktır.

\section{Yöntem}

Türkiye'de ageism konusu henüz çok yeni incelenmeye başlamıştır. Daha çok derleme şeklinde olmak kaydıyla, gençlerin veya öğrencilerin yaşlılık algısı ve sağlık personelinin ageism düzeyi üzerine çalışmalar mevcuttur (Çilingiroğlu, \& Demirel, 2004; Akdemir, Çınar, \& Görgülü, 2007; Vefikuluçay, 2008; Yılmaz, \& Özkan, 2010; Güven, Muz, \& Ertürk, 2012; Koç et. alii., 2013; Özdemir, \& Bilgili, 2014). Ancak, yaşlı bakım personelinin ageism düzeyi Türkiye'de görgül olarak henüz incelenmemiş bir konudur. Dolayısıyla, bu çalışma, Türkiye'de bakım sektöründe ageism konusuna bir giriş niteliği de taşımaktadır.

Bu çalışmada, Antalya'da bulunan, özel ve kamuya ait huzurevi ve bakım evlerinin tamamında, toplam 13 kurumdaki bakım personeliyle (sertifikalı bakıcı, bakım teknikeri ve hemşire) standart bir soru formu kullanılarak yüz yüze görüşmeler gerçekleştirilmiştir. Anket tekniği kullanılarak gerçekleştirilen görüşmeler, 2013 yılı Temmuz ve Ağustos aylarında tamamlanmıştır.

\subsection{Araştırmanın Evreni ve Örneklemi}

Araştırma evreni, Antalya İli'nde bulunan, özel ve kamuya ait, 13 huzurevi ve bakım evinde çalışmakta olan toplam 244 bakım personelinden oluşmaktadır. Araştırmanın evrenini oluşturan kurumlardan 3'ü özel, 2'si kamuya ait huzurevi ve kalan 8 tanesi özel bakımevi statüsündedir. Antalya'daki bakımevleri, genellikle engellilere yönelik ve her yaş grubuna hizmet veren kurumlardır. Bu kurumlar araştırmaya dahil edilmeden önce, halihazırda kurumlarda yaşlı 
bakım alıcılarının bulunup bulunmadığı kontrol edilmiş ve tüm kurumlarda yaşlı bakım alanların tespiti yapıldıktan sonra araştırma kapsamına alınmıştır. Araştırma kapsamında kurumlarda çalışan 244 personelin tamamına ulaşılması hedeflenmiştir. Öncelikle Aile ve Sosyal Politikalar Bakanlığı Antalya İl Müdürlüğü’nden yasal izinler alınmış, daha sonra her bir kurumun yöneticisinden tekrar izin alınmıştır. Bakım verenler, kurumsal izinler alınmış olmasına rağmen, gönüllülük esasına dayalı olarak çalışmaya davet edilmişlerdir. Çalışmaya katılmak istemeyen ya da tereddüt yaşayan kişiler araştırma kapsamı dışında bırakılmıştır. Böylece araştırma, etik ilkelere özen gösterilerek sürdürülmüştür ve toplamda 102 bakım personelinin, gönüllülük esasına dayalı olarak araştırmaya katılımı sağlanmıştır.

\subsection{Soru Formları}

Araştırmanın süresince yüz yüze gerçekleştirilen görüşmelerde, katılımcılara iki standart soru formu uygulanmıştır. Bunlardan ilki Sosyo-demografik Bilgi Anketi ve diğeri ise Fraboni Ageism Ölçeği'dir.

Sosyo-demografik Bilgi Anketi: Katılımcıların, yaş, cinsiyet, eğitim düzeyi, meslekteki tecrübe süresi, mevcut işyerlerindeki tecrübe süresi, mesleki statüsü gibi verileri toplamak amacyyla uygulanmıştır.

Fraboni Ageism Ölçeği: Fraboni tarafından 1990 yılında geliştirilmiş, Kutlu ve diğerleri (2012) tarafından Türkçe güvenilirlik ve geçerlilik çalışması yapılmış, en bilinen ageism ölçeğidir. Türkçe çevirisi 25 maddeden oluşan ölçekte, her soru 1-kesinlikle katılıyorum, 2-katılmıyorum, 3-katılıyorum, 4-kesinlikle katılıyorum şeklinde 4 seçenek ile kodlanmıştır. Ancak, ifadelere verilen yanıtlarda nötr bir noktanın (neutral position) olmayışı değerlendirme bakımından sorunludur. Zira, Anderson (1990) iki sebepten nötr noktanın bulunması ve ölçeğin 5'li likert tipi olması gerektiğini belirtmektedir. Birincisi nötr nokta olmaksızın, kimi katılımcılar maddeyi boş bırakmakta ya da tutumlarını yansıtmayan herhangi bir noktayı işaretlemektedirler. İkincisi ise, nötr bir durum olmadığı zaman, nötr olmayan durumlara cevap veren katılımcıların oranı, nötr bir durum olduğunda, bunun dışında kalan seçeneklere cevap verenlerle aynıdır (Köklü, 1995). Sayılan bu nedenlerden dolayı tüm ifadeler 5'li likert olarak uygulanmıştır.

Ölçeğin orijinal versiyonunda güvenilirlik düzeyi (Croanbach Alfa katsayısı) 0,83 ve Türkçe uyarlanmış halinde ise 0,84'tür (Kutlu, Küęük, \& Fındık, 2012). Kutlu ve diğerleri (2012) tarafından Türkçe'ye uyarlanmış ölçeğin kimi ifadelerinde tespit edilen çeviri hataları nedeniyle, orijinal ölçek yeniden değerlendirilmiş, ifadelerin Türkçe'ye çevirisi yeniden yapılmıştır. Pilot çalışma gerçekleştirilerek, Türkçe'ye çevrilen ifadeler test edilmiş ve orijinal ölçekteki gibi 29 maddenin tamamı araştırma sırasında kullanılmıştır. Ancak analiz neticesinde dört madde $(2,8$, 22 ve 24) güvenilirlik düzeyini olumsuz etkilediği için, bu çalışmada analizlerde yer almamıştır.

\subsection{Verilerin Analizi}

Yaşlı bakım personelinin ageism düzeylerini boyutlarını belirlemek amacıyla, öncelikle ölçeğin faktör analizi ve güvenilirlik analizleri gerçekleştirilmiştir. Ardından, betimsel analizler gerçekleştirilmiş, hangi alt boyutun, hangi sosyo-demografik özelliğe göre farklılık gösterdiğini belirlemek amacıyla bağımsız örneklem t-testi ve One-Way Anova testleri uygulanmıştır. Böylece bakım personelinin yaşlanma ve yaşlılığa ilişkin tutumları, ageism düzeyleri analiz edilmiştir. Daha sonra, bu çalışmanın ana sorusuna yanıt vermek üzere Lojistik Regresyon analizi uygulanmıştır. Lojistik Regresyon analiziyle ageism düzeyini belirleyen faktörlerin nelerden oluştuğu değerlendirilmiştir. 


\section{Bulgular}

\subsection{Betimsel Analizler}

Türkiye'de yaşlı bakım personeli yaşlılara karşı nasıl bir tutum sergilemektedir? Bu soruya yanıt vermek üzere, ageism ölçeğinin güvenilirlik analizleri yapılmıştır. Aşağıdaki tabloda ölçeğe ait güvenilirlik analizi sonuçları ve alt boyutların temel özellikleri sunulmaktadır.

Tablo 1. Agesim Ölçeği Alt Boyutları Güvenilirlik Analizi Sonuçları ve Temel İstatistikler

\begin{tabular}{|l|c|c|c|}
\hline Boyutlar & Cronbachs’ Alpha & Ortalama & Standart Sapma \\
\hline Önyarg1 & 0,74 & 3,6 & 0,6 \\
\hline Kaçınma & 0,72 & 2,3 & 0,5 \\
\hline Ayrımcılık & 0,57 & 3,6 & 0,7 \\
\hline Ageism (Toplam) & 0,72 & 3,1 & 0,4 \\
\hline
\end{tabular}

Agesim ölçeği üç boyuttan oluşmaktadır; önyargı, kaçınma ve ayrımcılık boyutları güvenilirlik analizi ile değerlendirilmiş, üç alt boyutun da analiz neticesinde güvenilir düzeyde olduğu tespit edilmiştir (sırasıyla cronbach's alpha $=0,74 ; 0,72 ; 0,57$ ). Yukarıda yer alan tabloda, her bir alt boyuta ilişkin ortalamalar ve standart sapmalar da yer almaktadır. Ortalamalar, araştırmaya katılan bakım personelinin ageism düzeylerinin genel olarak hangi seviyede yer aldığını göstermesi bakımından önemlidir. Detaylı analizlere geçmeden önce, her bir alt boyut için bakım verenlerin ageism düzeyleri değerlendirilmelidir. Bu değerlendirmeler 1 ile 5 puan arasında değişen bir skalada gerçekleştirilecektir. 1 puan en düşük düzeyi ve 5 puan ise en yüksek düzeyi işaret etmektedir. Buna göre skalada yer alan eşik noktaları aşağıdaki gibi tespit edilmiştir. Bakım verenlerin ortalama ageism düzeyleri;

1,00-1,79 arasında yer alyyorsa çok düşük düzey

1,80-2,59 arasinda yer alıyorsa düşük düzey

2,60-3,39 yer aliyorsa orta düzey

3,40-4,19 yer alıyorsa yüksek düzey

4,20-5,00 yer alıyorsa çok yüksek düzey olarak sınıflanmaktadır (Arun, 2008).

Ageismin önemli boyutlarından birisi olarak ölçülen önyargı düzeyleri bu araştırmaya katılan bakım verenler arasında ortalama 3,6 puana $(\mathrm{ss}=0,6)$ sahiptir. Bu ortalama puan, yukarıda belirtilen skalada yüksek düzeyde yer almaktadır. Önyargı düzeyine benzer olarak, bakım personelinin yaşlanma ve yaşlılığa karşı ayrımcı tutumları da dikkat çekici biçimde yüksektir. Araştırmaya katılan bakım personelinin ayrımcı tutumlarının ortalaması 3,6 puandır ( $(\mathrm{s}=0,7)$. Yüksek düzeyde ayrımcı tutum sergileyen bakım personeli, aynı zamanda yaşlanma ve yaşlılığa ilişkin yüksek düzeyde önyargıya sahiptir. Ageismin bir başka önemli boyutu da kaçınmadır. Kaçınma, yaşlıyla iletişime geçmekten kaçınmayı ölçmekte, ihmal ve görmezden gelme tutumlarını tetiklemektedir. Bu bakımdan değerlendirildiğinde bakım personelinin ortalama kaçınma puanları yukarıda verilen skalada düşük düzeyde yer almaktadır (ortalama $=2,30 ; \mathrm{ss}=0,5$ ). Ne var ki, düşük düzeyde çıkması kaçınmanın olmadığı anlamına gelmez, bakım personeli meslekleri ve gündelik işleri gereği yaşlılarla sürekli temas etmeleri gereken bir konumdadır. Bu nedenle, işin doğası gereği kaçınma gerçekleşemez. Yaptıkları işin doğası ve mahiyeti düşünüldüğünde, halihazırda sahip olunan kaçınma düzeyinin de, ihmal ve görmezden gelmeyi tetikleyebilecek düzeyde olduğu anlaşılacaktır. Sonuç olarak, ilk bulgular, araştırmaya katılan bakım personelinin yaşlanma ve yaşlılığa ilişkin olumsuz tutumlara sahip olduklarını göstermektedir. Bu bulgu yaşlı 
bireye bakım veren bir meslek grubu için oldukça çarpıcıdır ve dikkatle değerlendirilmelidir.

$\mathrm{Bu}$ noktada, analizleri derinleştirerek, hangi kişisel ve mesleki özelliklerin olumsuz tutumları etkilediği incelenmelidir. Aşağıdaki tabloda, toplumsal cinsiyet, eğitim ve mesleki deneyime göre bakım verenlerin ageism düzeylerinin analizi sonucu elde edilen bulgular yer almaktadır.

Tablo 2. Seçilmiş Göstergelere Göre Bakım Personelinin Yaşlıya Karşı Tutumları

\begin{tabular}{|c|c|c|c|c|c|}
\hline Değişkenler & $\mathbf{N}$ & Önyargı & Kaçınma & Ayrımcılık & $\begin{array}{c}\text { Ageism } \\
\text { (Toplam) }\end{array}$ \\
\hline \multicolumn{6}{|l|}{ Cinsiyet } \\
\hline Kadın & 81 & 3,6 & 2,34 & 3,6 & 3,0 \\
\hline Erkek & 21 & 3,6 & 2,15 & 3,6 & 3,0 \\
\hline \multicolumn{6}{|c|}{ Eğitim Düzeyi } \\
\hline İlkokul & 39 & $3,7^{*}$ & 2,4 & 3,7 & 3,2 \\
\hline Ortaokul & 15 & 3,7 & 2,4 & 3,4 & 3,1 \\
\hline Lise & 34 & 3,5 & 2,3 & 3,7 & 3,1 \\
\hline Üniversite & 14 & $3,2^{*}$ & 1,9 & $3,3^{*}$ & $2,7^{*}$ \\
\hline \multicolumn{6}{|c|}{ Mesleki Deneyim (Sektördeki toplam çalışma süresi, Yıl) } \\
\hline 1 y1ldan az & 24 & 3,6 & 1,9 & 3,9 & 2,9 \\
\hline $1-4$ y1l & 54 & 3,6 & 2,4 & 3,5 & 3,1 \\
\hline 5 yıl ve üzeri & 24 & 3,5 & 2,4 & 3,6 & 3,1 \\
\hline
\end{tabular}

Bakım personelinin ageism, önyargı, kaçınma ve ayrımcılık düzeylerinin cinsiyete göre farklılık gösterip göstermediğini test etmek üzere bağımsız örneklem t-testi, eğitim düzeyi ve meslekteki tecrübe süresine göre farklılık gösterip göstermediğini test etmek için One-Way Anova testleri uygulanmıştır. Yıldız işaretinin $\left(^{*}\right)$ bulunduğu değerler 0,05 düzeyinde istatistiksel olarak anlamlı bir farklılığa işaret etmektedir.

Tablo 2'de görüldüğü üzere, ageism, önyarg1, kaçınma ve ayrımcıllı düzeyleri, cinsiyete göre farklılık göstermemektedir. Kadın ya da erkek olsun, bakım personeli ageist bir tutuma sahiptir. Ancak, eğitim düzeyi ageismi etkileyen bir faktördür. Üniversite mezunu bakım personelinin, ilkokul, ortaokul ve lise mezunu olan personele göre ageism düzeyleri daha düşüktür $(\mathrm{p}=0,001)$. Ageismin boyutları itibariyle değerlendirildiğinde, ilkokul mezunlarının üniversite mezunlarına göre yaşlılara karşı daha önyargılı olduğu anlaşılmaktadır $(\mathrm{p}=0,033)$. Ancak, kaçınma ve ayrımcılık boyutları, eğitim düzeyine göre istatistiksel olarak anlamlı farklılıklar göstermemektedir (sırasıla; $\mathrm{p}=0,051 ; \mathrm{p}=0,090$ ). Yine de, ortalama puanlara dikkat edilmesi gerekir. Zira, ortalama puanlara bakıldığında, hangi eğitim seviyesine sahip olursa olsun bakım personelinin yaşlıya karşı yüksek düzeyde ayrımcı bir tutum sergilediği anlaşılmaktadır (Ortalama=3,3 ile 3,7 arasında). Bununla birlikte, bakım sektöründe geçirilen yıllar itibariyle kazanılan deneyimin ageism düzeyine bir etkisi olmadığı tespit edilmiştir. Bakım personeli ister 10 y1l üzerinde deneyime isterse 1 ylllık deneyime sahip olsun, ageist bir tutum sergilemektedir (Ortalama $=2,9$ ile 3,1 arasinda).

\subsection{Ageismi Etkileyen Faktörler}

Literatürde, kişisel özellikler (Kropf, Cummings, \& DeWeaver, 2000; Soderhamn, Lindencrona, \& Gustavsson, 2001; Herdman, 2002; Hweidi, \& Al-Hassan, 2005; Topaz, \& Doron; 2013) çalışma ortamı (Hope, 1994; Pursey, \& Luker, 1995; Nolan, Davis, \& Brown, 2002; McLafferty, \& Morrison, 2004; Doherty, Mitchell, \& O'Neill, 2011) ve bakım personelinin yasal haklarının 
ihlali (Banazak et alii, 2000; Yamada, 2002; Evers et alii, 2002; Buchan, \& Seccombe, 2006; Humphries et alii, 2008; Doherty, Mitchell, \& O’Neill, 2011; Leung et alii, 2013; McKenziea, \& Brown, 2014) ageismi etkileyen faktörler olarak tespit edilmektedir. Bu araştırma kapsamında da Türkiye' de yaşlı bakım personelinin yaş ve toplumsal cinsiyet gibi kişisel özellikleri, sektördeki ve işyerindeki çalışma süreleri (deneyimleri) ageismi etkileyen faktörler olup olmadığı analiz edilecektir. Öte yandan bakım personelinin yasal haklarının ihlal edilmesi Türkiye'de bu alanda yapılan çalışmalarda değerlendirilmeyen bir başka boyutu oluşturmaktadır. Aşağıda ortaya konan kavramsal modelde yasal hakların ihlal edilmesinin nasıl bir etki yarattığ da değerlendirilmektedir.

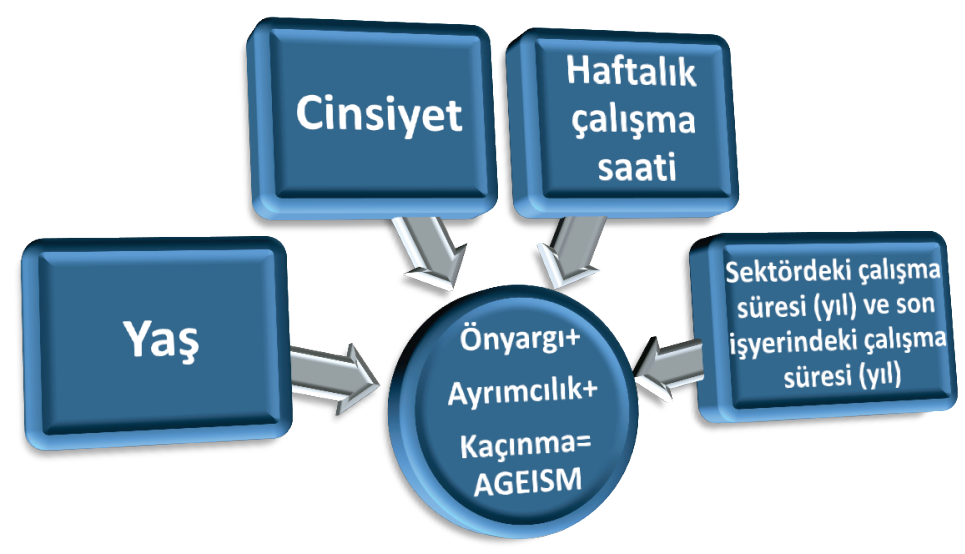

Fig. 1. Ageismi etkileyen faktörler

Analizlerde önyargı, ayrımcılık ve kaçınma boyutlarından oluşan ageism düzeyi bağımlı değişken olarak ele alınmıştır. Her bir alt boyut ve alt boyutların oluşturduğu ageism düzeyi ayrı ayrı, toplam 4 farklı model olarak doğrusal regresyon analiziyle test edilmiştir. Ancak, doğrusal regresyon analizi neticesinde, ageism ve alt boyutlarının yukarıda belirtilen bağımsız değişkenlerle doğrusal bir ilişki göstermediği anlaşılmıştır $(p>0,05)$. Bunun üzerine doğrusal olmayan ilişkileri analiz etme kabiliyetine sahip lojistik regresyon tekniği kullanılarak yukarıdaki kavramsal model analiz edilmiştir. Analize dahil edilen bağımlı değişkenler sırasıyla şu şekildedir;

Tablo 3. Lojistik Regresyon Analizinde Yer Alan Değişkenler

\begin{tabular}{|c|c|c|}
\hline \multirow{4}{*}{$\begin{array}{l}\text { Bağımlı } \\
\text { değişkenler }\end{array}$} & Ageism & \multirow{4}{*}{$\begin{array}{l}\text { Ordinal düzeyde. 1-2,99 arasındaki puanlar } 0 \\
\text { (yok) ve 3,0-5,0 arasındaki puanlar } 1 \text { (var) } \\
\text { olarak yeniden kodlanmıştır. }\end{array}$} \\
\hline & Önyarg1 & \\
\hline & Ayrımcılık & \\
\hline & Kaçınma & \\
\hline \multirow{6}{*}{$\begin{array}{l}\text { Bağımsız } \\
\text { değişkenler }\end{array}$} & Yaş & İnterval düzeyde. \\
\hline & Toplumsal cinsiyet & Nominal düzeyde. (1) Kadın ; (2) Erkek. \\
\hline & Eğitim seviyesi & $\begin{array}{l}\text { Ordinal düzeyde. (1) İlkokul, (2) Ortaokul, (3) } \\
\text { Lise, (4) Üniversite. }\end{array}$ \\
\hline & $\begin{array}{l}\text { Mesleki deneyim (Sektördeki } \\
\text { toplam çalışma süresi/yıl) }\end{array}$ & İnterval düzeyde. \\
\hline & Son işyerindeki çalışma süresi/yıl & İnterval düzeyde. \\
\hline & $\begin{array}{l}\text { Son işyerindeki haftalık çalışma } \\
\text { süresi/saat }\end{array}$ & $\begin{array}{l}\text { Ordinal düzeyde. (1) Yasal süre sınırları içinde, } \\
\text { (2) Yasal sürenin üzerinde (46 saat ve üzeri). }\end{array}$ \\
\hline
\end{tabular}


Tablo 4. Bakım Personelinin Ageism Düzeyini Etkileyen Faktörler (Lojistik Regresyon)

\begin{tabular}{|c|c|c|c|c|c|c|c|c|c|c|c|c|c|c|c|c|}
\hline \multirow{2}{*}{$\begin{array}{l}\text { Bağımsız } \\
\text { değişkenler }\end{array}$} & \multicolumn{4}{|c|}{ Ageism } & \multicolumn{4}{|c|}{ Önyarg1 } & \multicolumn{4}{|c|}{ Kaçınma } & \multicolumn{4}{|c|}{ Ayrımcılık } \\
\hline & $\beta$ & $\begin{array}{c}\operatorname{Exp} \\
. \beta\end{array}$ & $\begin{array}{l}\text { Wald' } \\
\text { s }\end{array}$ & $\mathrm{p}$ & $\beta$ & $\underset{\beta}{\operatorname{Exp} .}$ & Wald's & $\mathrm{p}$ & $\beta$ & $\begin{array}{c}\text { Exp. } \\
\beta\end{array}$ & Wald's & $\mathrm{p}$ & $\beta$ & $\underset{\beta}{\operatorname{Exp} .}$ & Wald's & $\mathrm{p}$ \\
\hline $\begin{array}{l}\text { Mesleki deneyim } \\
\text { (Sektördeki toplam } \\
\text { çalışma süresi/yıl) }\end{array}$ & 0,26 & 1,29 & 3,75 & $\mathbf{0 , 0 5}$ & 0,07 & 1,07 & 0,39 & 0,53 & 0,29 & 1,33 & 8,76 & $\mathbf{0 , 0 0 3}$ & $-0,01$ & 0,99 & 0,004 & 0,95 \\
\hline $\begin{array}{l}\text { Son işyerindeki } \\
\text { çalışma süresi/yıl }\end{array}$ & $-0,29$ & 0,75 & 3,82 & $\mathbf{0 , 0 5}$ & $-0,03$ & 0,97 & 0,05 & 0,83 & $-0,28$ & 0,76 & 4,66 & $\mathbf{0 , 0 3}$ & 0,20 & 1,23 & 1,72 & 0,19 \\
\hline Yaş & $-0,03$ & 0,98 & 1,33 & 0,25 & $-0,04$ & 0,96 & 1,52 & 0,22 & $\mathbf{0 , 0 3}$ & 1,03 & 0,76 & 0,04 & $-0,04$ & 0,97 & 1,36 & 0,24 \\
\hline $\begin{array}{l}\text { Haftalık çalışma } \\
\text { saati }(46+)\end{array}$ & 0,69 & 2,00 & 1,87 & 0,17 & 1,09 & 2,97 & 3,45 & 0,06 & 0,47 & 1,59 & 0,31 & 0,58 & 1,29 & 3,66 & 4,64 & $\mathbf{0 , 0 3}$ \\
\hline \multirow[t]{2}{*}{ Cinsiyet (kadın) } & 1,01 & 2,76 & 3,31 & $\mathbf{0 , 0 7}$ & $-0,32$ & 0,73 & 0,20 & 0,65 & $-0,59$ & 0,55 & 0,66 & 0,42 & 0,28 & 2,40 & 2,01 & 0,16 \\
\hline & \multicolumn{4}{|c|}{$\begin{array}{l}\text { Bağımlı değişken: Ageism } \\
\text { Cox \& Snell=0,111; Nagelkerke } \\
\text { Square= } 0,151 \\
\text { Tahmin oranı: } \% 67,6\end{array}$} & \multicolumn{4}{|c|}{$\begin{array}{l}\text { Bağımlı değişken: Önyarg1 } \\
\text { Cox \& Snell=0,045; Nagelkerke } \\
\text { Square }=0,072 \\
\text { Tahmin oranı: } \% 81,4\end{array}$} & \multicolumn{4}{|c|}{$\begin{array}{l}\text { Bağımlı değişken: Kaçınma } \\
\text { Cox \& Snell=0,112; Nagelkerke } \\
\text { Square= } 0,198 \\
\text { Tahmin oranı: \%86,3 }\end{array}$} & \multicolumn{4}{|c|}{$\begin{array}{l}\text { Bağımlı değişken: Ayrımcılık } \\
\text { Cox \& Snell=0,075; Nagelkerke } \\
\text { Square }=0,124 \\
\text { Tahmin oranı: } \% 82,4\end{array}$} \\
\hline
\end{tabular}


Lojistik regresyon analizi sonuçlarına göre, önyargı, kaçınma ve ayrımcılık alt boyutlarından oluşan ageist tutumu etkileyen 3 önemli faktör ortaya çıkmaktadır. Sektördeki çalışma süresi (y1l), son işyerindeki çalışma süresi (yıl) ve toplumsal cinsiyet, ageist tutumu etkileyen en önemli faktörlerdir. Öyle ki, sektördeki çalışma süresinde her 1 yıllık artış, ageist tutumu 1 kat artırmaktadır. Öte yandan, son işyerlerindeki çalışma süresi arttıkça, ageist tutumun 1 kat azaldığı görülmektedir. Ayrıca, kadın bakım personeli, erkeklere göre 2 kat daha ageist tutuma sahiptir.

Ageist tutumu oluşturan 3 alt boyut ayrı ayrı incelendiğinde; önyargı ve ayrımcılık alt boyutlarında benzer bir faktörün etkili olduğu tespit edilmektedir. Hem önyargıyı hem ayrımcı tutumu etkileyen bu faktör, işyerindeki haftalık çalışma süresidir. Yasal çalışma saatinin üzerinde çalışmak zorunda bırakılan bakım personelinin, 3 kat daha fazla ayrımcı tutuma sahip ve yaşlıya karşı 3 kat daha fazla önyargılı oldukları anlaşılmaktadır. Bakım personelinin kaçınma düzeyleri incelendiğinde ise üç önemli faktörün kaçınma üzerinde etkili bir rol oynadığı görülmektedir. Bakım verenin sektördeki çalışma süresi arttıkça kaçınmanın da 1 kat arttığı, ancak son işyerindeki çalışma süresi arttıkça kaçınmanın tam tersi 1 kat azaldığ1 görülmektedir. Ayrıca bakım personelinin yaşı arttıkça, yaşlılara karşı daha kaçınmacı bir tutum sergilemektedirler.

\section{Tartışma ve Sonuç}

Bakım personelinin cinsiyet ve yaş gibi kişisel özellikleri ve uzun çalışma saatleri ageist tutumları artırırken, mesleki bazı özellikler ageism düzeyini azaltmaktadır. Ageist tutumu etkileyen faktörler üç önemli başlık altında tartışılabilir: Deneyim, haftalık çalışma saati ve kişisel özellikler. Deneyim, sektördeki toplam çalışma süresi ve son işyerindeki çalışma süresi olarak değerlendirildiğinde, ageist tutumu azaltan ya da artıran etkiler göstermektedir. Bu bakımdan deneyimin mutlaka detaylı değerlendirilmesi gereklidir. Haftalık yasal çalışma saatinin aşılması ise, bakım personelinin ageist tutumlarını pekiştiren, verimliliği azaltan ve yaşam kalitesini olumsuz etkileyen en önemli faktör olarak görünmektedir. Son olarak toplumsal cinsiyet ve yaş gibi temel kişisel özelliklere göre ageist tutumlar değişkenlik göstermektedir.

\subsection{Deneyim: Bir Mesele İki Farklı Etki}

Deneyim ageist tutumu etkileyen önemli faktörlerden birisidir. Sektördeki deneyim süresinin her 1 yıllık artışı ageist tutumu 1 kat artırmaktadır. Öte yandan, mevcut işyerlerindeki deneyim süresi arttıkça, ageist tutumun 1 kat azaldığı görülmektedir. Bu ilginç bir bulgudur. Zira sektördeki deneyim süresi yaşlıya karşı olumsuz tutumu pekiştirirken, mevcut işyerindeki deneyim süresi yaşlıya karşı tutumu olumlu biçimde etkilemektedir. Öyleyse, deneyim süresi iki farklı yüzü olan bir meseledir. Her ne kadar, Reyna, Goodwin ve Ferrari’nin (2007) gerçekleştirdiği araştırmada deneyim ve yaşlıya karşı önyargı arasında bir ilişki bulunmamışsa da, McLafferty ve Morrison'un 2004 yılında gerçekleştirdikleri çalışmada deneyimli hemşirelerin değişen ölçülerde olsa da yaşlıya karşı olumlu tutum sahibi oldukları tespit edilmektedir. Bununla birlikte Griffiths ve Venturatto (2011), demans hastası yaşlılara destek veren deneyimli personelin daha olumlu bir tutum sergilediklerine işaret etmektedir. Ne var ki, literatürde yapılan çalışmaların deneyimi, sektörde geçirilen ve en son çalışılan kurumda geçirilen toplam çalışma süresi olarak ayırmadan analizlere dahil ettikleri görülmektedir. Oysa, deneyim, sektördeki toplam çalışma süresi ve son çalışılan kurumda geçirilen süre biçiminde ayrı faktörler olarak analizlere dahil edilmelidir. Zira bizim gerçekleştirdiğimiz bu araştırmada sektörde kazanılan deneyimin olumsuz etkisi gözlenmektedir. "Bakım sektöründeki ve son iş yerindeki çalı̧̧ma süresinin birbirinden farklı iki etki göstermesinin nedeni nedir?" sorusuna verilebilecek yantlar, 
deneyimin farklı etkilerini anlaşılır kılacak ve olumsuz tutumu pekiştiren etmenlerin ayıklanmasını sağlayacaktır.

\section{2. Çalışan Hakkı: Yasal Çalışma Süresi}

4857 nolu İş Kanunu'nun 63. Maddesine göre, çalışma süresi haftalık en fazla 45 saat ve günlük en fazla 11 saatle sınırlıdır (İş Kanunu, 2003, madde: 63). Ancak bizim araştırmamız sırasında, bakım personelinin bu sürelerden daha uzun süre çalıştığı gözlenmiştir. Lojistik regresyon analizi, bakım personelinin yasal sürenin üzerinde çalışmasının, onları yaşlılara karşı 1 kat daha önyargılı kıldığını ortaya koymaktadır. Literatürde, bakım personellerinin yasal sürenin üzerinde çalıştığ 1 tespit edilmektedir (Banazak et alii, 2000; Yamada, 2002; Leung et alii, 2013). Buna bağlı olarak, bakım personelinin haftalık çalışma süresi arttıkça, yaşlı sakinlere karşı daha agresif tutum sergilediği görülmektedir (Evers et alii, 2002). Bununla birlikte, ageist tutumların artması, yaşlıya hizmet veren kurumların hizmet kalitesini, toplumdaki pozitif algısını ve çekiciliğini, olumsuz etkilemektedir (Buchan, \& Seccombe, 2006; Humphries et alii, 2008; Doherty, Mitchell, \& O’Neill, 2011).

\subsection{Kişisel özellikler: Yaş ve Toplumsal Cinsiyet}

$\mathrm{Bu}$ çalışmada, bakım personelinin yaşı arttıkça, kaçınmacı tutumlarının da arttığı görülmüştür. Literatürde, bazı sağlık ve bakım personellerinin yaşı ilerledikçe, yaşlı bireye karşı tutumlarının olumsuz bir hale geldiği bildirilmektedir (Soderhamn, Lindencrona, \& Gustavsson, 2001, Herdman, 2002; Hweidi, \& Al-Hassan, 2005; Topaz, \& Doron, 2013). Öte yandan, bir çalı̧smada, yaş arttıkça yaşlılara karşı olumsuz tutumların azaldığı tespit edilmiştir (Evers et alii, 2002). Birbirinden farklı bu bulguların varlığı, bu konuda boylamsal verilere ve derinlemesine analizlere ihtiyaç duyulduğunu ortaya koymaktadır.

Toplumsal cinsiyet ageismi etkileyen bir diğer faktördür. Analiz sonuçlarına göre, kadın bakım personeli, erkeklerden daha ageist bir tutum sergilemektedirler. Cinsiyet birçok çalışmada da yine yaşlılara karşı tutumda belirleyici faktörlerden birisi olarak ortaya çıkmaktadır (Adelman, Greene, \& Charon, 1991; Lookinland, \& Anson, 1995; Soderhamn et alii, 2001; Hweidi, \& Al-Hassan, 2005; Topaz, \& Doron; 2013).

\subsection{Uygulamaya Yönelik Öneriler}

$\mathrm{Bu}$ çalışma, Antalya'da yaşlılara hizmet veren bakım kurumlarındaki yaşlı bakım personelinin ageism düzeyini belirlemek amacıyla gerçekleştirilmiş kesitsel bir araştırmanın bulgularını değerlendirmektedir. Elde edilen bulgular ve bunlara bağlı tartışmalar, bakım meselesi üzerine boylamsal ve çok boyutlu çalışmalara ihtiyaç olduğunu da ortaya koymaktadır. Kurumsal bakım personeli, yaşlı bireylerle doğrudan etkileşim halinde olması nedeniyle bakımın kalitesi açısından önemli bir role sahiptirler. Ancak, yaşlılıkla ilgili kalıp düşünceler ve önyargılar, bakımın kalitesini olumsuz etkilemekte; hem bakımı sunanın hem de bakım alanın yaşam kalitesini azaltmaktadır. Bu nedenle, bilhassa bakım personelinin eğitimlerinin kurumsallaşması, hizmet içi eğitimlerle ve sosyo-psikolojik açıdan desteklenmesi, sertifika programıyla bakım verme yetkisinin sınırlandırılması, bakımın denetiminin titizlikle gerçekleşmesi, yasal olarak çalışma şartlarının belirlenmesi ve pratikte uygulanmasının sağlanması yerine getirilmesi gereken en temel gerekliliklerdir. Temel ihtiyaçların karşılanması, bakım sürecini, hem bakımı veren hem de alan için insan haklarına yaraşır bir düzeye çekeceği gibi, bireylerin yaşam kalitesinin de kuşaklararası çatışmaya neden olmadan artırılmasını sağlayacaktır. 


\section{KAYNAKÇA}

T. C. Aile ve Sosyal Politikalar Bakanlığı: Engelli ve Yaşlı Hizmetleri Genel Müdürlüğü. (2013). From Engelli ve Yaşlı Hizmetleri Genel Müdürlüğü: www.eyh.gov.tr

Adelman, R. D., Greene, M. G., \& Charon, R. (1991). "Issues in Physician-Elderly Patient Interaction". Ageing and Society, 11/2, 127-148. doi:http://dx.doi.org/10.1017/S0144686X00003974

Akdemir, N., Çınar, F. İ., \& Görgülü, Ü. (2007). "Yaşlıların Algılanması ve Yaşlı Ayrımcılığı”. Turkish Journal of Geriatrics, 10/4, 215-222.

Anderson, G. (1990). Fundamentals of Educational Research. London: The Falmer Press.

Arun, Ö., (2008). "Yaşlı Bireyin Türkiye Serüveni: Kaliteli Yaşlanma İmkanı Üzerine Senaryolar". Gaziantep Üniversitesi Sosyal Bilimler Dergisi, 7/2, 313-330.

Arun, Ö. (2013). "International Spotlight: Developing Gerontological Social Policy Agenda for Turkey". The Gerontologist, 53/6, 891-897. DOI:gnt071v1-gnt071.

Arun, Ö., (2014). "Disability in Turkey: The Risks in Being Disabled for Accessing Educational Opportunities". Mediterranean Journal of Humanities, 4/1, 53-62. DOI:10.13114/MJH.201416423

Arun, Ö., (2014). 'Que Vadis' “Türkiye? 2050’ye Doğru Yaşlanan Türkiye’yi Bekleyen Riskler”. Selçuk Üniversitesi Sosyal Bilimler Enstitüsü Dergisi, 32, 1-12.

Arun, Ö., \& Çakıroğlu-Çevik, A., (2013). "Quality of Life in an Ageing Society: A Comparative Analysis of Age Cohorts in Turkey". Zeitschrift füt Gerontologie und Geriatri, 46/8, 734-739. DOI:10.1007/s00391-013-0502-z

Banazak, D. A., Mickus, M., Averill, M., \& Colenda, C. C. (2000). "Herding Cats: Barriers to Implementing a Nurse Aide Educational Program”. Ann Longerm Care, 8, 68-71.

Başbakanlık Mevzuatı Geliştirme ve Yayın Genel Müdürlüğü. (2003). İ̧̧ Kanunu. Retrieved 29 9, 2014, from Resmi Gazete: http://www.resmigazete.gov.tr/eskiler/2003/06/20030610.htm\#1

Behar, C. (2006). "Demographic Developments and "Complementarities": Ageing, Labor and Migration". Turkish Studies, 7/1, 17-31.

Bektaş, G., \& İlhan, N. (2008). "Huzurevlerinde Çalışan Hemşirelerin Tükenmişlik Düzeyleri”. Turkish Journal of Geriatrics, 11/3, 128-135.

Brown, R. (2010). "Prejudice Its Social Psychology”. Prejudiced Individuals. R. Brown, II/14-18. West Sussex, United Kingdom: Wiley-Blackwell.

Breckler, S. J. (1984). "Empirical Validation of Affect, Behavior, and Cognition As Distinct Components of Attitude". Journal of Personality and Social Psychology, 47/6, 1991-1205. Doi:10.1037/00223514.47.6.1191

Buchan, J., \& Seccombe, I. (2006). "Worlds apart? The UK and international nurses". Paper commissioned by the Royal College of Nursing, Publication code, 3, 049.

Butler, R. N. (1969). “Ageism: Another Form of Bigotry”. The Gerontologist, 9, 243-246.

Butler, R. N. (1989). "Dispelling Ageism: The Cross-Cutting Intervention". American Academy of Political and Social Sciences, 503/1, 138-147.

Butler, R., \& Lewis, M. (1973). Aging and Mental Health: Positive Psychological Approaches. Saint Louis: C.V. Mosby Press.

Caporael L. R., (1981). "The Paralanguage of Caregiving: Baby Talk to the Institutionalized Aged". Journal of Personality and Social Psychology, 40, 876-884.

Chaudhury, H. (2008). Remembering Home: Rediscovering the Self in Dementia. Baltimore: The John Hopkins University Press.

Clark, A., (2009). Ageism and Age Discrimination in Social Care in the United Kingdom. London. Centre for Policy on Ageing.

Cuddy, A. J., \& Fiske, S. T. (2002). "Doddering but Dear: Process, Content, and Function in Stereotyping of Older Persons". In T. D. Nelson, Ageism: Stereotyping and Prejudice Against Older Persons, $17-$ 32. London: The Mit Press.

Çilingiroğlu, N., \& Demirel, S. (2004). "Yaşlılık ve Yaşlı Ayrımcılı̆̆gı". Turkish Journal of Geriatrics, 
7/4, 225-230.

Çimen, M., Şahin, B., Akbolat, M., \& Işık, O. (2012). “Özel Bakım Merkezinde Çalışan Personelin Tükenmişlik ve İş Doyum Düzeylerine Yönelik Bir Çalışma”. Acıbadem Üniversitesi Sağlık Bilimleri Dergisi, 3, 24.

Doherty, M., Mitchell, E. A., \& O'Neill, S. (2011). “Attitudes of Healthcare Workers Towards Older People in a Rural Population: A Survey Using the Kogan Scale". Nursing Research and Practice, 2011, 1-7. Doi: 10.1155/2011/352627

Dozois, E. (2006). Ageism a Review of Literature. Calgary: Word on Street Consulting Ltd.

Eagly, A. H., \& Chaiken, S. (1998). “Attitude Structure and Function”. In G. Lindzey, D. Gilbert, \& S. T. Fiske, The Handbook of Social Psychology. New York: McGraw-Hill.

Emiroğlu, O. N., \& Yıldırım, N. (2007). "Huzurevi Çalışanlarının Yaşlıda Düşme Riskine İlişkin Görüşleri”. Turkish Journal of Geriatrics, 10/4, 184-196.

Evers, W., Tomic, W., \& Brouwers, A. (2002). Aggressive Behaviour and Burnout Among Staff of Homes for the Elderly. International Journal of Mental Health, 11/1, 2-9.

Fraboni, M., Saltstone, R., \& Hughes, S. (1990). "The Fraboni Scale of Ageism (FSA): An attempt at a More Precise Measure of Ageism”. Canadian Journal on Aging, 9/2, 55-56.

Giray, H., Meseri, R., Saatli, G., Yücetin, N., Aydın, P.,; Uçku, R., (2008). "Türkiye'ye İlişkin Yaşlı Sağlığı Örgütlenmesi Model Önerisi”. Tsk Koruyucu Hekimlik Bülteni, 7/1, 81-86.

Griffiths, S. G., \& Venturato, L. (2011). "Care Staff Attitudes And Experiences Of Working With Older People With Dementia”. Australasian Journal on Ageing, 30/4, 186-190. doi:10.1111/j.17416612.2010.00470.x

Güven, Ş. D., Muz, G. U., \& Ertürk, N. E. (2012). “The Attitudes of University Students Towards Elderly Discrimination and the Relation of These Attitudes With Some Variables". Journal of Anatolia Nursing and Health Sciences, (2), 99-105.

Humphries, N., Brugha, R., \& McGee, H. (2008). “Overseas Nurse Recruitment: Ireland As an Illustration of the Dynamic Nature of Nurse Migration”. Health Policy,87/2, 264-272. Elsevier Publisher.

Herdman, E. (2002). "Challenging the Discourses of Nursing Ageism”. International Journal of Nursing Studies, 39/1, 105-114.

Hewstone, M. (1989). Causal Attribution: From Cognitive Processes to Collective Beliefs. Oxford: Basil Blackwell.

Hope, K. W. (1994). “Nurses’ Attitudes Towards Older People: A Comparison Between Nurses Working in Acute Medical and Acute Care of Elderly Patient Settings". Journal of Advanced Nursing, 20/4, 605-612.

Hweidi, I. M., \& Al-Hassan, M. A. (2005). “Jordanian Nurses' Attitudes Toward Older Patients in Acute Care Settings". International Nursing Review, 5/3, 225-232.

İzgi, M. C., Çoban, M., Kapçı, E. G., \& Yalım, N. Y. (2013). "Huzurevi Çalışanlarının Yaşlı Mahremiyetine İlişkin Tutumları: Bir Ölçek Geliştirme Çalışması”. Türk Geriatri Dergisi, 16/2, 172-176.

Kemper, S. (1994). "Elderspeak: Speech Accommodations to Older Adults". Aging and Cognition, 1/1, 17-28.

Koç, A., Yıldırım, R., Gürcü, M., \& Vefikuluçay, D. (2013). “Assessing Young University Students’ Behaviour Regarding Age Discrimination". The Annals of Eurasian Medicine, 1/3, 49-55.

Köklü, N. (1995). “Tutumların Ölçülmesi ve Likert Tipi Ölçeklerde Kullanılan Seçenekler”. Ankara Üniversitesi Ë̆itim Fakültesi Dergisi, 28/2,90.

Kutlu, Y., Küçük, L., \& Findık, Ü. Y. (2012). "Pyschometric Properties of the Turkish version of the Fraboni Scale of Ageism". Nursing and Health Sciences, 14, 466.

Kropf, N. P., Cummings, S. M., \& DeWeaveri, K. L. (2000). "Knowledge of and Attitudes toward Aging among Non-elders: Gender and Race Differences”. Journal of Women \& Aging, 12 (1/2), 76-91. Georgia State University, Social Work Faculty Publications.

Lantis, K., Green, C. P., \& Joyce, S. (2002). "Providers and Quality of Care". New Perspectives on Quality of Care, 3, 1-8. 
Leung, J. L., Sezto, N. W., Chan, W. C., Cheng, S. P., Tang, S. H., \& Lam, L. C. (2013). "Attitudes and Perceived Competence of Residential Care Homes Staff About Dementia Care". Asian Journal of Gerontology \& Geriatrics, 8/1, 21-29.

Lewis, T., Barnes, L. L., Bienas, J. L., Lackland, D. T., Evans, D. A., \& Lean, C. F. (2009). "Perceived Discrimination and Blood Pressure in Older African Americans and White Adults". Journal of Gerontology: Medical Sciences, 64 A/9, 1002-1008.

Lookinland, S., \& Anson, K. (1995). Perpetuation of Ageist Attitudes Among Present and Future Health Care Personnel: Implications for Elder Care. Journal of Advanced Nursing, 21/1, 47-56.

Lovell, M. (2006). "Caring for the Elderly: Changing Perceptions and Attitudes". Journal of Vascular Nursing, 24/1, 22-26.

Mandıracıoğlu, A., \& Çam, O. (2004). "Huzurevi Çalışanlarının Sorunları ve Yaşlılar Hakkında Görüşleri”. Türk Geriatri Dergisi, 7/1, 29-32.

McGlane, E., \& Fitzgerald, F. (2005). Perceptions of Ageism in Health and Social Services in Ireland. Dublin: National Council on Ageing and Older People.

McKenziea, E. L., \& Brown, P. M. (2014). "Nursing Students' Intentions to Work in Dementia Care: Influence of Age, Ageism, and Perceived Barriers". Educational Gerontology, 40/8, 618-633. Doi: $10.1080 / 03601277.2013 .863545$

McLafferty, I., \& Morrison, F. (2004). "Attitudes Towards Hospitalized Older Adults". Journal of Advanced Nursing, 47/4, 446-453.

Nelson, T. D. (2002). Ageism: Stereotyping and Prejudice Against Older Persons. Cambridge, MA: MIT Press.

Nelson, T. D. (2005). “Ageism: Prejudice Against Our Feared Future Self”. Journal of Social Issues, $61 / 2,207-221$

Nolan, M., Davis, S., \& Brown, J. (2002). Longitudinal Study of the Effectiveness of Educational Preparation to Meet the Needs of Older People and Carers. Final Report to the English National Board for Nursing, Midwifery and Health Visiting, University of Sheffield, Sheffield, UK.

Özçakar, N., Kartal, M., Dirik, G., Tekin, N., \& Güldal, D. (2012). "Yaşlılara Bakım Verenlerde Tükenmişlik ve İlgili Faktörler: Yaşlı Bakımevlerinde Çalışanları Neler Etkiler?”. Turkish Journal of Geriatrics, 15/3, 266-272.

Özdemir, Ö., \& Bilgili, N. (2014). “Ageism in Health Care”. Gülhane Medical Journal, 56/2, 128-131.

Pamuk, D. (2013). "Kurumsal Bakım Sektöründe Ageism ve İş Memnuniyeti: Antalya Örneği". Yayınlanmamıı̧ Lisans Bitirme Tezi. Gerontoloji Bölümü. Antalya: Akdeniz Üniversitesi.

Pursey, A., \& Luker, K. (1995). “Attitudes and Stereotypes: Nurses' Work With Older People”. Journal of Advanced Nursing, 22/3, 547-555.

Quinn, M. J., \& Tomita, S. K. (1986). Elder Abuse and Neglect: Causes, Diagnosis and Intervention Strategies. New York: Springer.

Reyna, C., Goodwin, E. J., \& Ferrari, J. R. (2007). "Older Adult Stereotypes Among Care Providers in Residential Care Facilities: Examining The Relationship Between Contact, Eduaction, And Ageism". Journal of Gerontological Nursing, 33/2, 50-55.

Ryan E. B., Hummert M. L., Boich L. H., (1995). "Communication Predicaments of Aging: Patronizing Behavior Toward Older Adults". Journal of Language and Social Psychology, 14, 144-166.

Soderhamn, O., Lindencrona, C., \& Gustavsson, S. M. (2001). "Attitude Toward Older People Among Nursing Students and Registered Nurses in Sweden". Nurse Education Today, 21/3, 225-229.

Şimşek, L. (1995). "İş Tatmini”. Verimlilik Dergisi, 12, 91.

Topaz, M., \& Doron, I., (April 15, 2013) "Nurses' Attitudes Toward Older Patients in Acute Care in Israel”. OJIN: The Online Journal of Issues in Nursing, 18/2. Doi: 10.3912/OJIN.Vol18No02PPT01

Türkiye İstatistik Kurumu. (2013). İstatistiklerle Yaşlllar 2012. Ankara: Türkiye İstatistik Kurumu Matbaası.

Ünalan, D., Soyuer, F., \& Elmalı, F. (2012). "Geriatri Merkezi Çalışanlarında Yaşlı Tutumunun Değerlendirilmesi”. Kafkas Tip Bilimleri Dergisi, 2/3, 115-120. Doi:10.5505/kjms.2012.15870 
Vefikuluçay, D. (2008). Üniversitede Öğrenim Gören Öğrencilerin Yaşlı Ayrımcıllı̆ına İlişskin Tutumları. Ankara: Doğum ve Kadın Hastalıkları Hemşireliği AD Doktora Tezi, Hacettepe Üniversitesi Sağlık Bilimleri.

Wade, S. (1999). "Promoting Quality of Care for Older People: Developing Positive Attitudes to Working With Older People". Journal of Nursing Management, 7 (6), 339-347.

Westerhof, G. J., \& Barrett, A. E. (2005). "Age Identity and Subjective Well-Being: A Comparison of the United States and Germany". The Journals of Gerontology, Series B: Psychological Sciences and Social Sciences, 60, 129-136. Doi:10.1093/geronb/60.3.S129

Weirds, E. C. (2004). "Identifying and Presenting Ageism Among Health-Care Professionals". International Journal of Therapy and Rehabilitation, 11/2, 56-60.

Yamada, Y. (2002). "Profile of Home Care Aides, Nursing Home Aides, and Hospital Aides: Historical Changes And Data Recommendations". The Gerontologist, 42/2, 199-206.

Yılmaz, E. \& Özkan, S. (2010). "Hemşirelik Öğrencilerinin Yaşlı Ayrımcıllğına İlişkin Tutumları". Maltepe Üniversitesi Hemşirelik Bilim ve Sanatı Dergisi, 3/2, 35-53. 